\title{
Bibliotecas públicas e uso das tecnologias de informação e comunicação para o desenvolvimento social
}

Public libraries and use of information and communication technologies for social development

Gilda Olinto

Doutora em Comunicação e Cultura pela Universidade Federal do Rio de Janeiro. Profa. Dra. do Programa de Pós-graduação em Ciência da Informação UFRJ/IBICT

Email: gilda@ibict.br

\section{Resumo}

Este artigo tem como foco a biblioteca pública e seu papel de instituição facilitadora do acesso e uso das tecnologias de informação e comunicação (TICs), especialmente da internet. Ao mesmo tempo em que as TICs se difundem e se tornam indispensáveis em todos os tipos de atividades, mantêm-se as evidências sobre as desigualdades de acesso e usos dessas tecnologias que acompanham de perto as outras desigualdades sociais. Reflexões sobre o papel das bibliotecas públicas neste cenário sugerem a redefinição das suas funções. Ênfase passa a ser dada, não apenas o atendimento das necessidades de informação do seu público, mas também na sua competência em informação, sua participação cívica e seu acesso ao e-governo. Focalizando o caso brasileiro, mostram-se evidências sobre o baixo acesso à internet no país, sobre as lan houses como principal local de acesso à internet pelos segmentos menos favorecidos, aspectos que reforçam o protagonismo das bibliotecas públicas como instituição facilitadora do uso das TICs.

Palavras-chave: Biblioteca pública. Uso da internet. Informação para a comunidade. Divisão digital. Uso de tecnologias de informação e comunicação.

\begin{abstract}
The role of social facilitator of internet use is here attributed to the Public Library. At the same time that information and communication technologies (ICTs), especially the internet, are constantly changing and becoming indispensable tools for everyday life, there are still strong evidences about inequality of access and use of these technologies, which accompany other social inequalities. In this scenario, the role of the public library, not only as a reference service provider, but as an institution also devoted to information literacy, and as provider of other information that promotes civic participation and access to e-government is pointed out here. These are activities that promote the development of democratic competence. In the Brazilian case, there are several reasons that reinforce the above mentioned roles for the public libraries: the still low home access to the internet in the country and the large use of LAN houses as the major internet access point by from lower status groups.
\end{abstract}

Keywords: Public Library. Internet use. Community informatics. Digital divide. Information and communication technology use.

\section{Introdução}

Assumindo a irreversibilidade do uso das tecnologias e informação e comunicação (TICs) e sua inserção na vida diária na atualidade, este artigo tem como foco a biblioteca pública brasileira no seu papel de instituição facilitadora do acesso e uso dessas tecnologias no país.

InCID: R. Ci. Inf. e Doc., Ribeirão Preto, v. 1, n.1, p. 77-93, 2010. 
Aborda-se aqui inicialmente a questão da relação entre uso das TICs e desenvolvimento social, considerando alguns autores da literatura internacional e nacional que lidam com este tema. Estes estudos nos apresentam informações contrastantes, pois as fortes evidências sobre contribuições das TICs para o aumento das oportunidades de vida dos indivíduos e desenvolvimento de comunidades parecem conviver com dados igualmente incisivos sobre a manutenção, ou até mesmo do acirramento das desigualdades sociais, incluindo a divisão digital.

Diante desses contrastes, e de resultados limitados observados em esforços voltados para a democratização das TICs, sobretudo em países em desenvolvimento, as abordagens ao tema tendem a destacar, cada vez mais, a importância dos fatores ambientais - sociais, culturais e políticos - envolvidos no problema, assim como a congregação de vários esforços para a superação da divisão digital.

A contribuição das bibliotecas públicas para a democratização do uso das TICs tem sido destacada, tanto em países desenvolvidos quanto em países em desenvolvimento. No mundo anglo-saxão essas novas incumbências parecem estar sendo bem absorvidas, apesar dos desafios de atuar num ambiente informacional em constante mudança que é a característica da internet. Os países em desenvolvimento, entretanto, especificamente o mundo latino-americano, incluindo o Brasil, se deparam com uma biblioteca pública pouco preparada para essas tarefas em vários sentidos. Mais destacada que as sérias carências de diversos tipos - financeiras, de infraestrutura e de recursos humanos - é a realidade de uma biblioteca pública invisível, com pouca tradição de uso, e pouco inserida na vida comunitária desses países.

Apesar dessas limitações, algumas análises e evidências, como as que serão aqui apresentadas, sugerem que a biblioteca pública em alguns países como o Brasil pode passar a se destacar como "instituição facilitadora" de uso das TICs.

\section{Internet, TICs e Desenvolvimento Social}

Após um período inicial em que se temiam os efeitos negativos da internet - como provocar o isolamento social -, são seus efeitos positivos que passaram a se destacar em estudos que focalizam seus múltiplos usos e suas consequências para o indivíduo: o acesso a recursos, o aumento do capital social, o envolvimento cívico são efeitos positivos atribuídos ao uso diário da internet em diversos estudos (WELLMAN; WAYTHORNTHWAITE, 2002; CASTELLS,

InCID: R. Ci. Inf. e Doc., Ribeirão Preto, v. 1, n.1, p. 77-93, 2010. 
2003; KATZ; RICE, 2002). Quando a análise passa do nível individual ao nível agregado considerando grupos ou comunidade - igualmente aparecem em destaque os benefícios das TICs relativos a aspectos como o empoderamento de grupos em desvantagem social, a formação de redes sociais na defesa de interesses de grupos, o desenvolvimento comunitário. Estes efeitos positivos têm sido detectados em diversos tipos de pesquisas utilizando-se de vários tipos de métodos: tanto estudos quantitativos, em que se busca identificar o quanto o uso da internet se relaciona a outros comportamentos e características de indivíduos ou grupos, quanto estudos qualitativos que procuram identificar atitudes e opiniões de indivíduos e membros de comunidades sobre o impacto da internet nas suas vidas. Independentemente dos benefícios que a rede pode trazer, não há mais como dispensá-la. Wellman, um dos pioneiros e mais prestigiados pesquisadores da rede virtual, considera que a internet é parte inseparável ou "imanente" da vida diária na atualidade. Além disso, as constantes mudanças que ocorrem nos tipos de uso que dela podem ser feitos parecem colocar a questão dos seus efeitos negativos como irremediavelmente defasadas (CASTELLS, 2003; FERNBACK, 2005; BISHOP, 2001; MEHRA et al, 2002; WELLMAN; HOGAN, 2004).

A expansão e a inevitabilidade da internet tornam mais dramáticas as evidências, recorrentemente destacadas em diversos estudos, tanto em países desenvolvidos quanto em desenvolvimento, indicando que as desigualdades do acesso e dos diversos tipos de usos da internet e das outras TICS acompanham de perto as desigualdades sociais. Exclusão social ou exclusão digital passam a ser termos intercambiáveis, pois estão altamente correlacionados, constituindo aspectos de um mesmo problema. Na perspectiva de Sorj (2003, p. 62), a divisão digital é uma dimensão da divisão social: “a exclusão digital representa uma dimensão da desigualdade social: ela mede a distância relativa do acesso a produtos, serviços e benefícios das novas tecnologias de informação e comunicação entre segmentos da população."

A gravidade do assunto é que recursos como a internet são instrumentos de acesso a outros recursos e podem contribuir para o acirramento da exclusão social. Os indivíduos e grupos socialmente privilegiados tendem a estar e se manter mais bem equipados e mais habilitados a aproveitar as vantagens da internet e da convergência das mídias. Assim, à medida que a tecnologia avança, e multiplicam-se seus recursos, multiplicam-se também as vantagens daqueles que têm melhor condições de aproveitar-se dessa tecnologia. Utilizar as TICs para várias finalidades, fazendo delas um uso efetivo; obter contatos e informações que vão proporcionar acesso a melhores serviços e melhores empregos; maximizar o potencial das TICs através do uso de tecnologia mais avançada são aspectos que têm se mostrado altamente 
relacionados às condições sociais dos usuários e a tecnologia a que têm acesso (GURSTEIN, 2003, DIMAGGIO; COHEN, 2005; SORJ, 2003).

As iniciativas voltadas para a democratização do uso das TICs e da internet - valorizadas tanto pela sua relevância no momento atual, quanto pela necessidade de combater as desigualdades sociais que as acompanham - mostram, entretanto, que não basta disponibilizálas, pois aspectos ambientais - socioculturais e políticos - são fundamentais para o sucesso das iniciativas.

Levar em conta as características do contexto em projetos que visam a introdução das TICs é um aspecto que vem sendo incentivado pela área de estudos denominada informática social, que teve na divisão digital um dos estímulos para seu desenvolvimento. A ideia-chave destes estudos é de que a introdução das TICs se dá num ambiente social e tecnológico determinado, e este tem influência decisiva sobre seus efeitos: o contexto cultural e institucional em que as TICS são introduzidas influencia a maneira como são desenvolvidas, como são implantadas e usadas, e a gama de consequências que geram (KLING, 1999). Não haveria, portanto, uma solução predeterminada e válida para qualquer ambiente em que as TICs são implantadas; as especificidades de cada contexto devem ser consideradas, além da adoção de uma perspectiva multidisciplinar. Assim, profissionais da ciência da informação, biblioteconomia, informática, comunicação, sociologia, e outras áreas, congregam-se em estudos e propostas de uso das TICS na superação da divisão digital e o desenvolvimento comunitário.

A relevância do envolvimento da comunidade que as envolve no sucesso de iniciativas que visam a introdução dessas tecnologias sugeriu a Gurstein (2003) a utilização de novo conceito e a especificação da área de estudos denominada de informática comunitária, que pode ser considerada um desdobramento ou uma sub-área da informática social. Na escolha do termo o autor, assumidamente, absorve a influência de estudos na área de informática social, além da contribuição advinda de abordagens que já têm longa tradição em ciência da informação: informação para a comunidade (DURRANCE, 1984; SILVA, 1989).

Cabe destacar aqui que não é apenas a comunidade local que se leva em consideração nas pesquisas e intervenções da informática comunitária. Segundo Williams e Durrance (2010), novos questionamentos e direcionamentos se impõem a esse campo de estudos devido ao fenômeno da globalização e à complexidade das constantes mudanças tecnológicas que estariam provocando múltiplas divisões digitais. Um aspecto que se destaca atualmente é a possibilidade 
de troca de experiências e dados, e a consequente viabilidade de se aprender com as práticas que ocorrem em contextos os mais diversificados (KLING, 1999; WILLIAMS; DURRANCE, 2010).

Nesta mesma linha de preocupação, e considerando a importância dos lugares públicos na redução da divisão digital, foi realizado um estudo comparativo entre 25 países em desenvolvimento com nível alto de desigualdade de acesso à internet. O cotejo das evidências indicou, por exemplo, que a vontade política do pessoal envolvido em iniciativas governamentais e a apropriação social das TICs são aspectos fundamentais na disseminação de seu uso em lugares públicos. Apropriação social das TICs significa que sua introdução se dá juntamente com a produção de conteúdos digitais de interesse da comunidade, e com o estímulo ao envolvimento da comunidade na definição de atividades, com ou sem o uso das TICs (GOMEZ; AMBIKAR; COWARD, 2009).

\section{A biblioteca pública como instituição facilitadora do uso das TICs e desenvolvimento social}

Antes de abordar os trabalhos que enfatizam a biblioteca pública como instituição facilitadora do uso das TICs, coloca-se a questão de seu papel e sua relevância diante das constantes mudanças tecnológicas e da crescente multiplicidade de fontes de informação atualmente acessíveis dos mais diversos lugares. A longo prazo, o que ela pode oferecer que seja realmente específico para o usuário no mundo globalizado? Segundo Waller e McShane (2008), há várias áreas de atuação que apontam para a sustentabilidade da biblioteca pública a médio e longo prazo. Prover informação para o cidadão e o encorajamento da sua participação cívica têm sido atribuições das bibliotecas públicas ${ }^{\mathrm{i}}$, atribuições estas que se mantêm com o advento das novas tecnologias, sobretudo levando em consideração que a competência em informação da população em geral é ainda limitada. Criar mecanismos para o desenvolvimento desta competência, incluindo sua dimensão digital, é um desafio que se coloca atualmente às bibliotecas públicas.

No que se refere especificamente à habilidade no uso de fontes de informação, questões como acessibilidade, confiabilidade, validade e autoridade dos conteúdos são tópicos relevantes do momento atual e que garantem um papel de destaque e duradouro às bibliotecas públicas como instituição e aos bibliotecários como profissionais. A manutenção e atualização destas práticas exigem, segundo os autores, uma atenção constante a um contexto permanentemente 
em mudança. Outra função da biblioteca pública que passa a se destacar com o acesso às TICs é a de agentes do e-governo, proporcionando e facilitando o acesso a informações sobre serviços e documentação governamentais.

Buscando uma classificação dos tipos de desafios da biblioteca pública na era digital, os autores acima mencionados consideram que estes são políticos - reforçar a democracia através do desenvolvimento da competência em informação e participação no e-governo - econômicos - promover a inovação e a competição na economia digital, especialmente em economias de pequeno porte - culturais - preservar a memória cultural (em diálogo com as formas digitais) e a especificidade cultural num mar de conteúdos globalizados - e éticos - assegurar características de domínio público no espaço digital garantindo equidade, acessibilidade e universalidade do ambiente virtual e ao mesmo tempo preservar essas características no espaço físico da biblioteca (WALLER; MCSHANE, 2008).

Para o mundo anglo-saxão a biblioteca pública tem sido considerada uma instituição fundamental na luta contra as desigualdades de acesso às TICs. Estudiosos chegam até a destacá-la como sendo a única ponte disponível para os que estão do lado desconectado da divisão digital (SCHEMENT, 2003). Certamente facilitam o desempenho desta tarefa o equacionamento de aspectos fundamentais, como recursos financeiros, instalações, equipamentos e mão de obra. Nos EUA em 2007, segundo grande levantamento encomendado pela American Library Association, mais de 99\% das bibliotecas públicas já ofereciam acesso público à internet, sendo esta bastante utilizada pela população em geral, especialmente por grupos em desvantagem social. E dados anteriores, de 2004, indicavam 7,5 workstations por biblioteca. Além disso, biblioteca pública americana é uma instituição que se destaca na vida das comunidades, sendo procurada pelos cidadãos regularmente: a maioria (53\%) dos americanos adultos foi à biblioteca pública nos últimos 12 meses anteriores à pesquisa. Ela também é o local de acesso público mais citado para localização de conteúdos e recursos na internet, incluindo acesso a governo. A biblioteca pública é utilizada na busca de soluções para problemas pessoais, especialmente na área de educação, na procura de informações sobre a comunidade, e é também utilizada para ativação de redes de apoio e para desenvolvimento de organizações locais (ESTABROOK; RAINIE, 2007; BERLOT et al., 2008).

Nos países em desenvolvimento, especificamente na America Latina e no Brasil, as bibliotecas públicas tipicamente não se inserem na vida comunitária. Sobre o Brasil, deste a década de 1970, analistas destacam que as atividades que estas instituições desenvolvem estão 
concentradas em apoio à educação escolar e à leitura (MIRANDA, 1978). As bibliotecas públicas brasileiras também são vistas por estudiosos como instituições que, pela sua concepção e estrutura administrativa, tendem a não envolver a comunidade em que atuam (MACHADO, 2007). Entretanto, o próprio desenvolvimento das tecnologias de informação e comunicação, assim como a realidade da divisão digital, sugerem a adoção de novos enfoques, assim como a diversificação dos papéis da biblioteca pública mesmo nesses contextos desfavoráveis.

Tendo como foco de análise as carências dos países com baixo acesso à internet, Haythornthwaite (2007) chama atenção para instituições que podem ser classificadas como facilitadores sociais na superação da divisão digital. Instituições, como escolas, e outros locais de acesso público como lan houses, poderiam estar entre esses facilitadores sociais, especialmente em locais em que a disponibilidade de computadores em casa é limitada. Entre essas instituições estariam também as bibliotecas públicas, consideradas um local privilegiado para a solução dos problemas de informação dos cidadãos, para o desenvolvimento da competência em informação entre a população e para a promoção da produção de conteúdo de interesse local. Redes sociais, tanto online quanto offline, que se formam espontaneamente nas comunidades seriam outro tipo de facilitadores sociais para a capacitação em TICs.

A formação ou ativação de redes sociais virtuais, com o apoio da biblioteca pública, para desenvolver atividades que visam o acesso da comunidade a informações sobre si mesma é um tema abordado pela literatura de ciência da informação desde o início de 2000. Apoiam-se essas iniciativas em estudos de redes sociais que, com ainda maior tradição, antecedem à presença e uso dos recursos da comunicação virtual. São trabalhos que mostram a relevância dessas redes no apoio a grupos com necessidades específicas e no desenvolvimento da comunidade cívica (MARTELETO; TOMAEL, 2005; HAYTHORNTHWAITE, 2010). A internet, entretanto, parece potencializar essas redes da mesma forma que aumenta as possibilidades de atuação das bibliotecas públicas. Comentando sobre os resultados de um amplo estudo sob provisão de serviços de informação para a comunidade com o uso da internet, Durrance e Pettigrew (2001, p.1) afirmam:

A internet provê novos meios de acesso à informação sobre a comunidade para o cidadão, meios esses que eram difíceis de obter no passado [...]. Nós identificamos uma grande amplitude de impactos dos serviços e sistemas virtuais de informação para comunidade nos cidadãos, nas organizações e na comunidade como um todo.

O aumento da habilidade das pessoas em obter informação, a mobilização de grupos e instituições para fornecimento ou troca de informações, em suma, o desenvolvimento ou 
construção da comunidade através da dinamização do fluxo de informação é o resultado esperado das redes sociais promovidas pelas bibliotecas públicas.

A análise das características das redes sociais incentivadas pelas bibliotecas, e seu papel no desenvolvimento da comunidade, é outro aspecto focalizado em pesquisas. Segundo Williams e Durrance (2010), redes sociais, especialmente aquelas caracterizadas por laços fortes entre os seus membros, parecem contribuir para o aumento do uso das TICs em comunidades de baixa renda.

A ênfase na função social das bibliotecas públicas e a busca do envolvimento da comunidade nas suas atividades são tópicos frequentemente mencionados em trabalhos sobre o tema realizados por estudiosos da América Latina, inclusive do Brasil. As grandes desigualdades sociais nestes países exigem, segundo esses autores, que as bibliotecas públicas deem destaque a esta sua função social e comunitária. As ações de informação se dão inseridas em um leque amplo de atividades, destacando-se entre estas a valorização das manifestações culturais da comunidade. Um aspecto também enfatizado por estas abordagens é não apenas que a comunidade se aproprie das atividades oferecidas, mas que passe a atuar e ter influência sobre a própria gerência da biblioteca:

A biblioteca deve se preocupar em ser o centro cultural e social da comunidade, engajando a comunidade na administração da biblioteca, tornando-a responsável pela organização de eventos, envolvendo-a na angariação de fundos para a biblioteca, determinando as prioridades de ação social e comunitária da biblioteca... (TARAPANOFF; SUAIDEN, 1995, p.160).

A adaptação da biblioteca às necessidades específicas da comunidade por ela servida é igualmente apontada por uma experiência de serviço de informação local em Antioquia, Colômbia, um caso bem-sucedido de coordenação de serviço de informação para a comunidade (BETANCUR, 2002a, 2002,b). O bibliotecário e outros profissionais envolvidos são vistos como leitores da realidade, tendo o desafio de ser simultaneamente um agente social, educador e mediador. Neste contexto, as bibliotecas públicas são instadas a buscar o seu próprio modelo de atuação, a buscar uma identidade própria. Ao mesmo tempo, atenção é dada ao uso das TICs, inclusive como um canal de circulação da cultura local, e à inserção da biblioteca pública no mundo global. Esta é, portanto, uma instituição que cumpre a dupla tarefa de estímulo ao desenvolvimento local e à formação de cidadãos numa perspectiva global 


\section{Uso da internet no Brasil: desigualdades, lugares públicos e bibliotecas públicas}

O aumento anual do acesso e uso da internet no Brasil, assim como da disponibilidade de computadores em residência, tem sido fantástico. Segundo dados do survey anual do Comitê Gestor da Internet (CGI), que é baseado numa amostra representativa da população do país, o número de domicílios com computador e acesso à internet, especialmente através da banda larga, assim como o numero de usuários crescem a altíssimas taxas anuais. Os dados para 2009 indicam que $43 \%$ dos brasileiros com 10 anos e mais utilizaram a internet nos três meses antes do levantamento, porcentagem indicando que dobrou a proporção de usuários em relação ao ano de 2005, quando as pesquisas do próprio CGI e do IBGE indicavam aproximadamente $21 \%$ da população com este mesmo tipo de acesso (COMITÊ, 2006, 2009; INSTITUTO, 2007, 2009).

O otimismo que nos incutem essas evidências se enfraquece substancialmente quando as análises passam a buscar identificar o perfil sociodemográfico daqueles que acessam e dos que usam a internet. As diferenças entre os variados estratos educacionais, de renda e de raça são ainda muito grandes, revelando a intensidade da divisão digital no país. Em 2005, enquanto apenas 4,5\% dos 83 milhões de brasileiros com menos de 10 anos de educação tinham acesso à internet, este acesso era garantido para $76 \%$ daqueles que tinham mais de 15 anos de educação. Diferenças semelhantes observam-se quando se focalizam os diferentes grupos de renda, e as análises também indicam que a população branca e os salários mais altos são os que apresentam números favoráveis. Uma dimensão clara da divisão digital diz respeito ao acesso a internet através de tecnologias mais avançadas, havendo claras diferenças entre os grupos de educação, renda e raça que têm acesso à banda larga. Algumas dessas diferenças que ainda aparecem nos dados para 2009 indicam que o fosso digital é uma realidade persistente (OLINTO, 2008; COMITÊ, 2006, 2009).

Outros ângulos da divisão digital são revelados nesses estudos quando se considera os diversos tipos de uso da internet na sua relação com as características socioeconômicas do usuário. As evidências mostram que os usos da internet para atividades que fazem sentido e que trazem benefícios para o indivíduo, como atividades educacionais e acesso a governo, estão altamente relacionados à educação e à renda dos usuários.

A divisão digital nacional aparece ainda mais dramática quando se busca o cotejo com países desenvolvidos. Tomando por base a população adulta (com mais de 18 anos), dados de 
2005 indicam que 80\% dos brasileiros ainda não tinham acesso à rede, enquanto nos EUA, no mesmo ano, $80 \%$ da população adulta já tinha acesso à internet. Neste mesmo ano, entre os jovens brasileiros (de 18 a 29 anos) 70\% ainda não tinham tido acesso à internet, enquanto nos EUA, no mesmo ano, 84\% dos jovens americanos já tinham acesso à internet.

Ainda considerando os jovens adultos brasileiros, pode-se observar que, no grupo de privilegiados que acessa a internet, a maioria o faz fora de casa. $\mathrm{O}$ uso da internet fora de casa, sobretudo em lan houses, é o que caracterizava a da maioria (55\%) dos 11 milhões de jovens adultos brasileiros que em 2005 acessavam a internet. Acesso em local público pago ainda é uma realidade para $44 \%$ dos usuários brasileiros em 2009. Somente $4 \%$ dos brasileiros utilizaram acesso público gratuito em 2009. E relacionando o local de acesso com a renda do usuário, vê-se que aqueles que pagam são os que não têm disponibilidade para fazê-lo: receber até um salário mínimo significa utilizar lan houses: realidade para $72 \%$ desses usuários. E estar na faixa de famílias que recebem mais de 5 salários mínimos significa utilizar a internet em casa: destes, apenas 24\% utilizam lan houses (COMITÊ, 2006, 2009; OLINTO, 2008; EASTABROOK; RAINIE, 2007).

Lan houses como principal local de acesso à internet para a população socialmente menos favorecida parece apresentar aspectos positivos e negativos. Como principal aspecto positivo, pode-se mencionar que são iniciativas privadas que respondem a uma demanda espontânea da sociedade e garantem acesso à internet a baixo custo para a população que não tem recursos para dispor de computador em suas residências. Além disso, elas preenchem um vazio institucional: a pouca disponibilidade e o efeito limitado das iniciativas públicas, como bibliotecas e telecentros com capacidade para atender as necessidades de informação da população e dar treinamento no uso das TICs.

Os telecentros e outras iniciativas públicas, incluídos em diversos programas de governo, embora visem o desenvolvimento da competência digital e de conteúdos voltados para as necessidades e interesses da comunidade, parecem estar funcionado mais como um local de encontro de jovens, apresentando características similares às lan houses (MADON et al., 2007).

Outra limitação dos telecentros e lan houses como pontos de acesso massivo à internet é o fato de serem mais frequentados por meninos do que pelas meninas - com ênfase em atividades lúdicas, como os jogos na internet - desta maneira contribuindo para a divisão digital de gênero e tendo efeito limitado no desenvolvimento da competência digital dos usuários em geral. Alguns estudos reforçam estas preocupações. No que se refere às diferenças de gênero no 
uso da internet, há tendências a redução no país e, assim como em outros países, até indícios de uso equivalente e até superior pelas meninas nos níveis iniciais de escolaridade. Entretanto, algumas evidências sugerem que um uso diferenciado por gênero pode se manter ou até se acentuar ao longo do tempo (OLINTO, 2008). Especificamente em relação às lan houses, análises de dados do IBGE (INSTITUTO, 2007) revelam que, entre estudantes, as meninas utilizam-na muito menos que os meninos, especialmente no ensino fundamental e no ensino médio. A maior diferença entre os sexos no uso das lan houses se dá no segundo segmento do ensino fundamental (antigo ginásio): enquanto mais de 37\% dos meninos as utilizam, apenas $26 \%$ das meninas o fazem. Se acrescentarmos aqui informações sobre a baixa orientação das meninas para as carreiras tecnológicas, incluindo com destaque as ocupações em TICs, que absorvem no Brasil apenas $20 \%$ das meninas, fica aqui sugerido que as diferenças de gênero no uso das lan houses não é um aspecto de pouca relevância (OLINTO, 2004).

As restrições e distorções que acompanham o uso massivo das lan houses no Brasil sugerem que o incentivo a essas iniciativas, embora válido, não substitui outras iniciativas que as complementam, com destaque para as bibliotecas públicas para garantir o acesso e o treinamento em TICs de grande parcela da população que não dispõe do equipamento em suas residências e/ou não estão habilitados para seu uso efetivo. No que diz respeito especificamente à presença das meninas, este ambiente seria particularmente favorável, devido ao prestígio da instituição e à presença da equipe de profissionais de informação. Recoloca-se, assim, a relevância das bibliotecas públicas como instituição facilitadora do uso das TICs; busca-se trazer ao primeiro plano as nossas pouco visíveis, porém numerosas, bibliotecas públicas como instituições facilitadoras no uso das TICs.

O país dispõe atualmente de 5.226 bibliotecas públicas, sendo que 1.656 foram implantadas nos últimos seis anos a partir do Programa Livro Aberto, coordenado pela Biblioteca Nacional. Este programa distribuiu kits para essas novas bibliotecas com um acervo básico de 2.000 títulos, além de equipamentos (BIBLIOTECA, 2008; DOMINGUES, 2009). Embora através deste programa cada biblioteca seja contemplada com apenas um computador nesse conjunto de bens, a possibilidade de se desenvolverem parcerias com organizações e programas públicos e privados tornaria essas novas bibliotecas locais ideais para a instalação de computadores com acesso à internet, formando bibliotecas-telecentros com possibilidade de virem a desempenhar as novas funções requeridas das bibliotecas públicas, conforme antes mencionado: atender a cidadãos com problemas específicos de informação contribuindo para o treinamento na sua competência em informação, tanto do público em geral quanto de 
estudantes; prover informações sobre e para a comunidade, contribuindo para seu desenvolvimento político, econômico e cultural; servir de agência do e-governo fornecendo informações sobre os seus serviços aos usuários, etc.

Neste ponto, cabe questionar sobre a capacitação atual do profissional nas bibliotecas públicas, incluindo seu treinamento no uso das TICs. O bibliotecário, o profissional tipicamente habilitado para atuar na biblioteca pública (no caso do Brasil uma exigência legal), tem sido a figura central no treinamento em TICs nas bibliotecas públicas dos países desenvolvidos, tarefa que exerce no seu trabalho diário de assistência aos usuários. Sobre esta sua tarefa nos EUA afirmou-se: "hoje em dia quase todas as bibliotecas públicas proveem treinamento básico em internet através de assistência individual dada por bibliotecários” (BILL, 2004, p.21). No Brasil, entretanto, pode-se questionar a preparação do bibliotecário para a função de treinamento no uso das TICs, tanto pelas características de sua formação quanto pelo perfil de sua atuação profissional. Entre os profissionais de informação, o bibliotecário é o que menos acesso tem a essas tecnologias: análise dos dados do IBGE/PNAD-2005 mostra que, enquanto quase $90 \%$ dos profissionais de comunicação já tinham acesso à internet no ano do levantamento, esse acesso envolvia apenas $60 \%$ dos bibliotecários do país (OLINTO, 2007b). Entretanto, soluções a curto e médio prazo podem ser concebidas para enfrentar este problema, como cursos de aperfeiçoamento e presença de equipes interdisciplinares nas bibliotecas públicas. Além disso, convém destacar a importância da presença do bibliotecário na biblioteca pública devido a aspectos da sua preparação técnica: um profissional formado para gerir a biblioteca e seu acervo e para lidar com diversos problemas relacionados à informação, tanto on-line quanto off-line.

\section{Considerações finais}

Procurou-se mostrar neste trabalho que a irreversibilidade das TICs, especialmente a internet, assim como o acesso a informações e benefícios que proporcionam, torna urgente a adoção de vários tipos de iniciativas para garantia de sua democratização.

Reflexões sobre o papel das bibliotecas públicas neste cenário sugerem a tendência à redefinição das suas funções, passando a destacar o acesso público à internet e a promoção, não apenas o atendimento das necessidades de informação do usuário, mas também sua competência em informação, sua participação cívica, seu acesso ao e-governo, contribuindo assim para o processo democrático.

InCID: R. Ci. Inf. e Doc., Ribeirão Preto, v. 1, n.1, p. 77-93, 2010. 
Focalizando o caso brasileiro, buscaram-se evidências que justificariam redobrar as atenções no uso das TICs para essas novas funções da biblioteca pública do país. As carências de acesso a computador e a internet foram inicialmente destacadas: a grande maioria da população ainda não tem acesso a essas tecnologias em suas residências, sendo que os segmentos socioeconômicos de nível mais baixo são os que mais se utilizam dos locais de acesso pago, como as lan houses. São também esses segmentos que fazem menos uso da internet e usam-na menos para finalidades que podem trazer melhores oportunidades, como obter informações sobre educação e a ter acesso ao governo. Destacamos aqui também para o fato de esses locais de acesso público serem menos utilizados pelas meninas, entre o público em idade escolar.

Apesar da pouca tradição de uso das bibliotecas públicas do país e da sua reduzida visibilidade enquanto instituição, outra razão destacada para se considerar as bibliotecas públicas como instituições facilitadoras do uso das TICS está na sua abrangência: dispõe-se hoje de 5.226 bibliotecas cadastradas no sistema de bibliotecas da Fundação Biblioteca Nacional, sendo que estas estão em vias de cobrir todos os municípios do Brasil.

A garantia de financiamento básico e de uma estrutura mínima e sustentável de acesso público à internet seriam condições necessárias, porém não suficientes, para o sucesso de iniciativas voltadas para a democratização da internet na biblioteca pública. As abordagens aqui apresentadas sugerem que este sucesso dependerá de um contexto político, social e cultural favorável, expresso nas atitudes e ações dos principais atores envolvidos. Um governo que revele conscientização do potencial de contribuição da biblioteca pública e das TICs no desenvolvimento social seria uma condição fundamental, assim como as atitudes e características dos profissionais atuantes na biblioteca. Com relação a esses últimos, sua disponibilidade e preparação para atuar, com enfoque interdisciplinar, nas atividades de comunicação e colaboração com o sistema de bibliotecas, no desenvolvimento da competência em informação do cidadão e no diálogo com a comunidade, tanto on-line quanto off-line, seriam outras condições básicas.

Finalizando, poder-se-ia destacar que nada foi dito aqui sobre os livros e a leitura, razão primordial da biblioteca pública. Evidentemente o uso da biblioteca pública como telecentro não pode competir com o uso da biblioteca como local do livro e da leitura. Mas este não parece ser um problema; estudos sugerem que interesses culturais não competem entre si, ao contrário, parecem se beneficiar mutuamente. $\mathrm{O}$ mesmo acontece com a internet, cujos efeitos negativos 
no hábito de leitura ainda não foram consistentemente sustentados. E há que destacar, ainda, a contribuição da internet para o acesso à literatura em geral, e às fontes bibliográficas para a pesquisa escolar em particular.

\section{Referências}

BERLOT, J.C. et al. Public Libraries and the Internet 2007: issues, implications and expectations. Library and information Science Research, v. 30, n.3, p. 175-184, 2008.

BETANCUR, A. M. La biblioteca pública em la perspectiva del desarrollo local: uma estratégia para la democracia. In: IFLA COUNCIL AND GENERAL CONFERENCE. 68., 2002, Glasgow. Proceedings... 2002a.

BETANCUR, A. M. Um lugar en el mundo: los servicios de información local en la biblioteca pública. Métodos de información, v.9, n.51, p 38-43, 2002 b.

BIBLIOTECA NACIONAL. Arquivo de dados do sistema nacional de bibliotecas públicas. 2008.

BILL \& MELLINDA GATES FOUNDATION. Towards equality of access: the role of public libraries in addressing the digital divide. 2004. Disponível em:

$<$ http://www.imls.gov/pdf/Equality.pdf> Acesso em: 09 ago. 2010

BISHOP, A. et al. Afya: social and digital technologies that reach across the digital divide. First Monday, v.6, n.4, April, 2001. Disponível em:

$<$ http://www.firstmonday.org/issues/issue6_4/bishop>. Acesso em: 18 ago. 2009.

CASTELLS, M.A. A galáxia da Internet: reflexões sobre a Internet, os negócios e a sociedade. Rio de Janeiro: Zahar. 2003.

COMITÊ GESTOR DA INTERNET NO BRASIL. Pesquisa sobre uso das tecnologias de informação e comunicação no Brasil. 2006. Disponível em: $<$ http://www.cetic.br/tic/2006/indicadores-2006.pdf $>$.

COMITÊ GESTOR DA INTERNET NO BRASIL. Pesquisa sobre uso das tecnologias de informação e comunicação no Brasil. 2009. Disponível em:

$<$ http://www.cetic.br/tic/2006/indicadores-2009.pdf $>$.

DIMAGGIO, P; COHEN, J. Information inequality and network externalities: a comparative study of the diffusion of television and the Internet. In: NEE, V.; SWEDBERG, R. The

Economic Sociology of Capitalism. Princeton: Princeton University, 2005. p. 227-267.

Disponível em: < http://www.russellsage.org/publications/workingpapers/infoineq/document >. Acesso em: 09 ago. 2010. 
DURRANCE, J.C.; PETTIGREW, K.E. Toward context-centered methods for evaluating public library networked community information initiatives. First Monday, v.6, n.4, 2001. Disponível em: <http://firstmonday.org/htbin/cgiwrap/bin/ojs/index.php/fm/search/results >. Acesso em: 18 ago. 2009.

DOMINGUES, S.M.M. Visão das bibliotecas públicas implantadas pela Fundação Biblioteca Nacional: Programa Livro Aberto 2004. In: CONGRESSO BRASILEIRO DE BIBLIOTECONOMIA E DOCUMENTAÇÃO, 23., 2009, Bonito. Anais... São Paulo: FEBAB, 2009.

DURRANCE, J.C. Community information services - an innovation at the beginning of its second decade. Advances in Librarianship, v. 13, p. 99-128, 1984.

EASTABROOK, L.; RAINIE, L. Information searches that solve problems: how people use the internet, libraries, and government agencies when they need help. Pew Internet \& American Life Project. Report. December, 30, 2007. Disponível em: <http://www.pewinternet.org/>. Acesso em: 18 ago. 2009

FERNBACK, J. Information technology, networks and community voices: social inclusion for urban regeneration. Information, Communication and Society, v.8, n.4, p. 482-502, Dec. 2005.

GOMEZ, R.; AMBIKAR, R.; COWARD, C. Libraries, telecentres and cybercafés: an international study of public access information venues. Performance Measurement and Metrics: an International Journal for Library and Information Services, v.10, n.1, p. 3348, 2009.

GURSTEIN, M. Effective use: a community informatics strategy beyond the Digital Divide. First Monday, v.8, n.12, 2003. Disponível em: <http://firstmonday.org/htbin/cgiwrap/bin/ojs/index.php/fm/article/view/1107/1027>. Acesso em: 09 ago. 2010.

HAYTHORNTHWAITE, C. Social facilitators and inhibitors to online fluency. In: HAWAII INTERNATIONAL CONFERENCE ON SYSTEM SCIENCES, 40., 2007, Big Island, Proceedings... IEEE, 2007. Disponível em: http://www.computer.org/portal/web/csdl/doi/10.1109/HICSS.2007.488 Acesso em: 09 ago. 2010.

HAYTHORNTHWAITE, C. Social networks and information transfer. In: BATES, M. J.; MAACK, M. N.; DRAKE, M.(Eds.). The encyclopedia of library and information science. NY: Taylor \& Francis, 2010. p. 4837-4847.

INSTITUTO BRASILEIRO DE GEOGRAFIA E ESTATÍSTICA. PESQUISA NACIONAL POR AMOSTRA DE DOMICÍLIOS 2005. Acesso à Internet e posse de telefone móvel celular para uso pessoal. Rio de Janeiro: IBGE, 2007. Disponível em: $<$ http://www.ibge.gov.br/home/estatistica/populacao/acessoainternet/internet.pdf > . Acesso em: 9 ago. 2010.

INSTITUTO BRASILEIRO DE GEOGRAFIA E ESTATÍSTICA. PESQUISA NACIONAL POR AMOSTRA DE DOMICÍLIOS 2008 - Acesso à Internet e Posse de Telefone Móvel 
Celular para Uso Pessoal. Rio de Janeiro: IBGE, 2009. Disponível em: http://www.ibge.gov.br/home/estatistica/populacao/acessoainternet2008/internet.pdf $>$. Acesso em 9 ago 2010

KATZ, J.E; RICE, R. E. Social consequences of Internet use: access, involvement and expression. Cambridge: MIT Press, 2002.

KLING, R. What is social informatics and why does it matter? D-Lib Magazine, v.5, n.1, 1999. Disponível em : http://www.dlib.org/dlib/january99/kling/01kling.html Acesso em: 09 ago. 2010.

MACHADO, E. Uma discussão acerca do conceito de biblioteca comunitária. Revista Digital de Biblioteconomia e Ciência da Informação, v.7, n. 1, p. 80-94, 2007. Disponível em: $<$ http://www.sbu.unicamp.br/seer/ojs/viewarticle.php?id=195\&layout=abstract $>$ Acesso em: 09 ag. 2010.

MADON, S. et al. Digital inclusion projects in developing countries: processes of institutionalization. In: INTERNATIONAL CONFERENCE ON SOCIAL IMPLICATIONS OF COMPUTERS IN DEVELOPING COUNTRIES, 9., 2007, São Paulo. Proceedings... São Paulo, 2007.

MARTELETO, R; TOMAEL, M.I. Metodologia de análise de redes sociais. In:VALENTIM, M. L. P.(Org.) Métodos qualitativos de pesquisa em ciência da informação. São Paulo: Polis, 2005. p. 81-100,

MEHRA, A, B. et al. Scenarios in the Afya Project as a Participatory Action Research (PAR) tool for studying information seeking and use across the Digital Divide. Journal of the American Society for Information Science and Technology, v.54, n.14, p. 1259-1266, 2002.

MIRANDA, A. A missão da biblioteca pública no Brasil. Revista de Biblioteconomia de Brasília, v.6, n.1, p. 69-75, 1978. Disponível em:

$<$ http://164.41.122.25/portalnesp/ojs-2.1.1/index.php/RBB/issue/view/18/showToc > Acesso em 09 ago. 2010

OLINTO, G. Gender differences in Internet use by Brazilian students: judicious girls and playful boys. In: CULTURAL ATTITUDES TOWARDS TECHNOLOGY AND

COMMUNICATION, 6., 2008, Nimes. Proceedings... Murdoch: Murdoch University. School of Information Technology, 2008, p. 106-116.

OLINTO, G. Internet access in Brazil: social context and science and technology professionals. In: THE AMERICAN SOCIETY FOR INFORMATION SCIENCE AND TECHNOLOGY ANNUAL MEETING, 70., 2007, Milwaukee. Proceedings... Milwaukee: ASIST, 2007.

OLINTO, G. Ocupações em tecnologia de informação e comunicação no Brasil. In: CONGRESSO LUSO-AFRO-BRASILEIRO DE CIÊNCIAS SOCIAIS, 8., 2004, Coimbra.Anais... Disponível em: <http://www.ces.uc.pt/lab2004/pdfs/GildaOlinto.pdf>. Acesso em: 09 ago. 2010.

SCHEMENT, J.R. Measuring What Jefferson knew and De Tocqueville saw: libraries as bridges across the Digital Divide. IT \& Society, v. 1, n. 4, p. 118-125, Spring 2003. 
SILVA, G. O. V. Biblioteca e estudos de comunidade. Ciência da Informação, v. 18, n.2, p. 151-154, 1989. Disponível em: http://revista.ibict.br/ciinf/index.php/ciinf/article/view/1367/993 Acesso em: 09 ago. 2010.

SORJ, B. Brasil@povo.com: a luta contra a desigualdade na sociedade da informação. Rio de Janeiro: Zahar/Unesco, 2003.

TARAPANOFF, K; SUAIDEN, E. Planejamento estratégico de bibliotecas públicas no Brasil: histórico, crise e perspectivas. Revista de Biblioteconomia de Brasília, v.19, n.2, p. 137-165, jul/dez. 1995. Disponível em: http://164.41.122.25/portalnesp/ojs-

2.1.1/index.php/RBB/issue/view/55 Acesso em 09 ago. 2010

WALLER, V.; McSHANE, I. Analysing the challenges for large public libraries in the twentyfirst century: a case study of the State Library of Victoria in Australia. First Monday, v. 13, n.12, Dec. 2008. Disponível em:

$<$ http://firstmonday.org/htbin/cgiwrap/bin/ojs/index.php/fm/article/view/2155/2060>

WILLIAMS, K.; DURRANCE, J. C. Community informatics. In: BATES, M. J.; MAACK, M. N.; DRAKE, M.(Eds.) Encyclopedia of Library and Information Sciences. New York: Taylor\&Francis, 20010. p. 1202-1208.

WELLMAN, B.; WAYTHORNTHWAITE, C. (Eds.). The Internet in everyday life. Oxford: Blackwell, 2002.

WELLMAN, B.; HOGAN, B. The immanent internet. In: MCKAY, J. R. (Ed.) Netting Citizens. Edinburgh: St Andrew's Press, 2004. p. 54-80.

\section{Agradecimento}

Agradeço ao $\mathrm{CNPq}$ pelo apoio financeiro ao projeto: Usos das tecnologias de informação e comunicação em bibliotecas públicas e desenvolvimento social.

\footnotetext{
${ }^{\text {i }}$ Os autores são pesquisadores da Swinburne University, Austrália, e se referem ao papel das bibliotecas públicas no mundo anglo-saxão que têm tradição na informação comunitária. Os autores destacam que a preocupação com a competência democrática e com a saúde da democracia tem orientado os serviços da biblioteca pública ao longo do tempo.
} 